\title{
O ACESSO À JUSTIÇA E O FORNECIMENTO DE PRESTAÇÕES ATINENTES À SAÚDE
}

\section{Rodrigo Gomes Flores ${ }^{1}$}

\section{RESUMO}

Este artigo analisará o acesso à justiça nas ações que pedem uma prestação do Estado referente à saúde e suas perspectivas, utilizando o método de revisão bibliográfica, jurisprudencial e da legislação. As leis asseguraram mecanismos para concretizar o acesso à justiça às pessoas necessitadas. Entretanto, estes mecanismos se mostraram insuficientes nas ações que pedem uma prestação da saúde. Portanto, foi preciso acrescentar novos preceitos para assegurar o acesso à justiça nestes casos especiais. Contudo, o número crescente de ações com esta temática, fez com que a administração e jurisdição buscassem arranjos institucionais, consagrando uma nova etapa do acesso à justiça.

Palavras-chave: Acesso à Justiça; Direito à Saúde; Poder Judiciário

\section{ACCESS TO JUSTICE AND THE PROVISION OF HEALTH BENEFITS}

\begin{abstract}
This article will examine access to justice in the actions that call for a state provision related to health and its prospects. It uses the method of literature review, jurisprudence and legislation. The laws ensured mechanisms to achieve access to justice to poor people. These mechanisms have proved insufficient in the actions that call for the provision of health. It was necessary to add new provisions to ensure access to justice in these cases. However, the growing number of actions to this subject, made the administration and jurisdiction to seek institutional arrangements, establishing a new stage of access to justice.
\end{abstract}

Keywords: Access to Justice; Health Care; Judiciary Power

\section{INTRODUÇÃO}

As constituições liberais do século XVIII asseguraram fundamentalmente o direito à igualdade, à vida e a propriedade. Entendia-se na época que, para atingir estes objetivos, bastava que o Estado não intervisse para assegurar os direitos, o que, contudo, revelou-se insuficiente para a concretização dos direitos fundamentais e o acesso à justiça.

Com o advento do Estado Democrático de Direito, exige-se hoje uma postura ativa do Poder Público para assegurar os direitos fundamentais ao cidadão, dentre eles o acesso à saúde. Desse modo, como condição de existência de um Estado Democrático de Direito não basta apenas a previsão de direitos, exige-se também um Poder Judiciário independente e preocupado com a efetivação dos direitos fundamentais. Com efeito, de nada adianta haver a

\footnotetext{
${ }^{1}$ Procurador do Município de Pelotas. Especialista em Direito Público pela Anhanguera/LFG. Mestrando em Direito e Justiça Social pela FURG
} 
previsão constitucional e legal dos direitos se o Poder Judiciário não se preocupa em assegurar efetivamente o acesso à justiça em relação aos direitos fundamentais, em especial o direito à saúde, eis que se assim não fosse, seria o mesmo que negá-los.

Neste sentido, diante das peculiaridades inerentes às ações judiciais que envolvem pedidos de uma prestação do direito à saúde, o Poder Judiciário brasileiro adotou uma série de procedimentos inovadores, com o fim de assegurar ao cidadão o acesso à justiça.

Portanto, este artigo utilizará o método da revisão bibliográfica, jurisprudencial e da legislação vigente e analisará, em primeiro lugar, a evolução do conceito de acesso à justiça, depois enumerará os obstáculos a serem transpostos para a sua efetivação, analisará as soluções práticas para os problemas de acesso à justiça no Brasil nas ações que pedem prestações da saúde do Poder Público e, por fim, tecerá considerações acerca de soluções que poderão contribuir com a efetivação do direito fundamental à saúde, sob a ótica do acesso à justiça.

\section{A EVOLUÇÃO DO CONCEITO DO ACESSO À JUSTIÇA}

O estudo do acesso à justiça se fundamenta no objetivo de tornar efetivos - e não meramente simbólicos - os direitos do cidadão comum. Para tanto, se exige reformas de amplo alcance e uma nova criatividade. $\mathrm{O}$ estudo do acesso à justiça recusa-se a aceitar como imutáveis quaisquer dos procedimentos e instituições que caracterizam a engrenagem da justiça. Assim, o conceito de acesso à justiça sofreu mudanças importantes, que reflete uma mudança equivalente no estudo e ensino do processo civil.

Cumpre dizer que nos estados liberais dos séculos dezoito e dezenove, os procedimentos adotados para a solução dos litígios refletiam a ideia essencialmente individualista dos direitos, então em voga naquela época. $\mathrm{O}$ direito ao acesso à proteção judicial limitava-se ao direito formal do indivíduo prejudicado de propor ou contestar uma ação. O entendimento era de que, embora o acesso à justiça pudesse ser um "direito natural", os direitos naturais não necessitavam de uma ação do Estado para sua proteção. Esses direitos eram considerados anteriores ao Estado; sua defesa exigia apenas que o Estado não permitisse que eles fossem infringidos por outros. Portanto, o Estado permanecia passivo como relação a problemas tais como a aptidão de uma pessoa para reconhecer seus direitos e defendê-los adequadamente, na prática.

Com efeito, a incapacidade que muitas pessoas têm de utilizar plenamente a justiça e as suas instituições não era preocupação do Estado naquele tempo. Assim como outros bens, a 
Justiça no sistema liberal só podia ser obtida por aqueles que pudessem enfrentar seus custos, aqueles que não pudessem fazê-lo eram considerados os únicos responsáveis pelo seu destino. Portanto, o acesso formal, mas não efetivo à justiça, correspondia à igualdade, apenas na lei, mas não efetiva.

Contudo, na medida que as sociedades do estado liberal cresceram em tamanho e complexidade, o conceito de direitos humanos passou a sofrer uma radical transformação. A partir do momento em que as ações e relacionamentos assumiram caráter mais coletivo que individual, as sociedades modernas necessariamente deixaram para trás a visão individualista dos direitos, refletidas nas "declarações de direitos", típicas dos séculos dezoito e dezenove. O movimento foi no sentido de reconhecer os direitos e deveres sociais dos governos, comunidades, associações e indivíduos.

Esses novos direitos são necessários para concretizar, ou melhor, tornar realmente acessíveis a todos os direitos antes proclamados. Dentre os novos direitos garantidos nas modernas constituições estão os direitos à saúde, ao trabalho e à educação. Assim, tornou-se lugar comum observar que a atuação positiva do Estado é imprescindível para assegurar o gozo de todos esses direitos sociais básicos.

Registre-se, ainda, que o direito de acesso à justiça, além de direito fundamental dos indivíduos catalogado na Constituição Federal de 1988, no art. 5º, inciso XXXV, é direito humano proclamado na Declaração Universal de Direitos Humanos de 1948, a qual garantiu uma proteção judicial efetiva a todos aqueles atos que violem os direitos fundamentais mediante um Tribunal independente e imparcial. Em consonância com a Declaração Universal dos Direitos do Homem está a Convenção Americana de Direitos Humanos Pacto de San José da Costa Rica, que dispõe que todos têm direito a uma proteção Estatal dos atos que violem seus direitos fundamentais reconhecidos pela Constituição, pela lei ou pela própria convenção.

Anote-se que o enfoque sobre o acesso - o modo pelo qual os direitos se tornam efetivos - caracteriza crescentemente o estudo do moderno processo civil. Por exemplo, a discussão teórica das várias regras do processo civil e como elas podem ser manipuladas em várias situações hipotéticas pode ser instrutiva, mas, sob essas descrições neutras, é costume ocultar o modelo frequentemente irreal das partes em igualdade de condições perante a corte, limitadas apenas pelos argumentos jurídicos que os experientes advogados possam defender. Contudo, o processo não poderia ser colocado no vácuo. Precisam os juristas, agora, reconhecer que as técnicas processuais servem a funções sociais. Sendo assim, uma tarefa 
fundamental dos processualistas modernos é expor o impacto substantivo dos vários mecanismos de processamento de litígios.

Com efeito, é necessário que o acesso à justiça seja interpretado como acesso à ordem jurídica justa. Deve-se efetivá-la com medidas de cunho processual e material que importem em prestação jurisdicional adequada, eficiente, de qualidade, responsável e comprometida para com os pilares democráticos assentados na Constituição Federal. Com isso quer-se dizer que deverá haver, necessariamente, diálogo entre o Juiz e as partes do processo, bem como se deve possibilitar ao cidadão a ampla comprovação do direito vindicado e o processo deve ser encerrando mediante decisão judicial fundamentada (CAPPELLETTI; GARTH, 2008, p. 112).

Verifica-se, portanto, que o conceito do acesso à justiça evoluiu em sincronia com a ideia dos direitos fundamentais. Nos seus primórdios, o acesso à justiça era estudo sob a ideia da igualdade absoluta, algo que se sabe ser impossível na situação concreta. Desse modo, o acesso à justiça passou a ser entendido como a efetivação de um sistema jurídico que pretenda assegurar e não apenas enunciar o direito dos cidadãos.

\section{OBSTÁCULOS A SEREM TRANSPOSTOS PARA A EFETIVAÇÃO DO ACESSO À JUSTIÇA}

Não obstante o efetivo acesso à justiça venha sendo crescentemente aceito como um direito social básico na sociedade moderna, o conceito de "efetividade" é, por si, algo vago. Efetividade perfeita, no contexto do direito substantivo, poderia ser expressa como a completa "igualdade de armas" - seria a garantia de que a conclusão final depende apenas os méritos jurídicos relativos das partes antagônicas em relação, sem levar em conta as diferenças que sejam estranhas ao Direito e que, no entanto, afetam a afirmação e reivindicação de direitos. Essa perfeita igualdade, obviamente, é utópica (CAPPELLETTI; GARTH, 2008, p. 15).

Assim sendo, a ideia de igualdade é utópica, eis que num mundo imperfeito e numa sociedade complexa e desigual como a nossa, muitas pessoas encontram dificuldade de concretizar o efetivo acesso à justiça. A seguir enumeraremos importantes exemplos que são barreiras ao acesso à justiça.

\subsection{1 CUSTAS E HONORÁRIOS ADVOCATÍCIOS}


O primeiro obstáculo que identificamos ao acesso efetivo à justiça é o das custas judiciais. A resolução de litígios, principalmente nos tribunais, é muito dispendiosa na grande maioria das sociedades modernas. O Estado paga o subsídio dos juízes e os vencimentos dos servidores, além de manter os prédios e outros recursos necessários aos julgamentos enquanto que os litigantes precisam suportar a grande proporção dos demais custos necessários à solução de uma lide, incluindo honorários advocatícios e custas judiciais.

O sistema legal brasileiro, assim como noutros países, ao vencido é imposto o ônus da sucumbência, devendo pagar honorários, custas e despesas processuais. Assim, torna- se claro que os altos custos de um processo judicial se tornam uma barreira importante ao acesso à justiça. Qualquer tentativa realística de enfrentar os problemas de acesso à justiça deve começar por resolver esta situação: os serviços do advogado são muito caros (CAPPELLETTI; GARTH, 2008, p. 15-18).

Sendo assim, a questão do custo, incluídas despesas, custas e honorários advocatícios da demanda é prioritária se quisermos conceder acesso à justiça às pessoas carentes.

\subsection{2 MOROSIDADE DO PODER JUDICIÁRIO}

O tempo de tramitação do processo é outra barreira para o acesso à justiça. Em muitos países, as partes que buscam uma solução judicial aos seus conflitos precisam esperar dois ou três anos, ou mais, por uma decisão exequível. A Convenção Europeia para Proteção dos Direitos Humanos e Liberdades Fundamentais reconhece explicitamente, que a Justiça que não cumpre suas funções dentro de "um prazo razoável” é, para muitas pessoas, uma justiça inacessível (CAPPELLETTI; GARTH, 2008, p. 19-20).

Anote-se que já no início do século passado, Rui Barbosa, na "Oração aos Moços" (CASA RUI BARBOSA, 2016), discurso que paraninfava os formandos da turma de 1920 da Faculdade de Direito do Largo de São Francisco, já advertia:

\footnotetext{
Os juízes tardinheiros são culpados, que a lassidão comum vai tolerando. Mas sua culpa tresdobra com a terrível agravante de que o lesado não tem meio de reagir contra o delinquente poderoso, em cujas mãos jaz a sorte do litígio pendente. Não sejais, pois, desses magistrados, nas mãos de quem os autos penam como as almas do purgatório, ou arrastam sonos esquecidos como as preguiças do mato.
}

O problema da morosidade da justiça não deixou de ser percebido pelo Congresso Nacional, vindo a Emenda Constitucional $n^{\circ} 45 / 04$ acrescentar no rol dos direitos fundamentais o inciso LXXVIII: “A todos, no âmbito judicial e administrativo, são 
assegurados a razoável duração do processo - judicial e administrativo - e celeridade de sua tramitação".

Tornando-se, portanto, assegurado o direito a um prazo razoável do processo um direito fundamental, qualquer discussão séria sobre a questão do acesso à justiça deve considerar mecanismos processuais e materiais que tornem a tramitação de um processo mais célere, sobretudo na área da saúde.

\subsection{3 POSSIBILIDADE DAS PARTES}

A "possibilidade das partes" é fundada na ideia de que algumas espécies de litigantes desfrutam de uma gama de vantagens estratégicas. Por exemplo, algumas organizações e pessoas que possuam grandes recursos financeiros têm vantagens óbvias ao propor ou defender demandas. Podem, igualmente, suportar as delongas do litígio. Estas capacidades, nas mãos apenas de uma das partes, pode ser uma poderosa arma. De maneira similar, uma das partes pode ser capaz de fazer gastos maiores que a outra e como resultado, apresentar seus argumentos de um método mais eficiente. Julgadores que não percebem este problema, apesar de suas outras e mais admiráveis características, exacerbam-no, por deixarem às partes a tarefa de obter e apresentar as provas, desenvolver e discutir a causa (CAPPELLETTI; GARTH, 2008, p. 21).

Competirá, assim, ao magistrado culto utilizar a equidade quando a balança pender apenas para um lado em razão da desigualdade econômica, social ou cultural.

\subsection{4 APTIDÃO PARA RECONHECER UM DIREITO}

Identifica-se a aptidão para reconhecer um direito e propor ação em sua defesa outro obstáculo ao acesso à justiça. A “capacidade jurídica” pessoal se relaciona com as vantagens de recursos financeiros e educação, meio e posição social. A “capacidade jurídica” enfoca várias barreiras que precisam ser pessoalmente superadas, antes que um direito possa ser efetivamente reivindicado através do nosso aparelho judiciário. Muitas (senão a maior parte) das pessoas comuns não podem - ou, ao menos, não conseguem - superar estas barreiras na maioria dos processos. Num primeiro estágio está a questão de reconhecer a existência de um direito juridicamente exigível. Trata-se de uma barreira fundamental séria para os despossuídos, mas não afeta apenas os pobres. Diz respeito a toda a população em muitas espécies de conflitos que envolvem direitos (CAPPELLETTI; GARTH, 2008, p. 22- 23). 
Em realidade a população, sobretudo aquela socialmente vulnerável, muitas vezes desconhece as leis, e assim deixa de lutar por seus direitos no Poder Judiciário.

\subsection{5 DISPOSIÇÃO PSICOLÓGICA DAS PESSOAS RECORREREM A PROCESSOS JUDICIAIS}

A falta de conhecimento sobre o direito ainda se relaciona com uma outra barreira importante: a disposição psicológica das pessoas recorrerem a processos judiciais. Mesmo os que sabem como encontrar aconselhamento jurídico qualificado podem não buscá- lo. Além dessa dificuldade existem ainda outras razões por que os litígios formais são considerados tão pouco atraentes. Formalismo, procedimentos complicados, ambientes intimidatórios como o dos tribunais, juízes e advogados, figuras tidas como opressoras, fazem com que o litigante se sinta perdido, um prisioneiro num mundo estranho (CAPPELLETTI; GARTH, 2008, p. 2325).

Definitivamente, os tribunais não são o ambiente natural da grande maioria da população, razão pela qual, muitas vezes ela prefere evitá-los, tornando mais distante o acesso à justiça.

\subsection{6 OS LITIGANTES EVENTUAIS E LITIGANTES HABITUAIS}

A existência de litigantes eventuais e litigantes habituais é outro empecilho ao acesso à justiça. Esta distinção corresponde, na maioria das vezes, à que se verifica entre indivíduos que costumam ter contatos isolados e pouco frequentes com o Poder Judiciário, com maior experiência judicial. As vantagens dos "habituais" são inúmeras: maior experiência com o Direito possibilita-lhes melhor planejamento do litígio, litigante habitual possui economia de escala, eis que possui mais processos, tem oportunidade de desenvolver relações informais com os membros do Poder Judiciário, pode diminuir os riscos da demanda por maior número de casos e poderá testar estratégias em determinados casos, de maneira a assegurar expectativa mais favorável em relação a casos futuros.

Portanto, a situação sugere que em função dessas vantagens, os litigantes institucionais são, sem dúvida, mais eficientes que os indivíduos. Há problemas menores em mobilizar as empresas com o fim de tirarem proveito de seus direitos, o que, com frequência, se dá exatamente contra as pessoas comuns que, em sua condição de consumidores, por exemplo, 
são as mais relutantes em procurar amparo no sistema judiciário (CAPPELLETTI; GARTH, 2008, p. 25-26).

No nosso estudo, que se ocupa com o acesso à justiça nas ações que pedem uma prestação estatal referente à saúde, é importante mencionar que o Estado brasileiro é o maior litigante do país (CONSULTOR JURÍDICO, 2015). Obviamente que esta situação concede ao Estado experiência que lhe confere uma evidente superioridade técnica diante do litigante eventual, sobretudo se for hipossuficiente economicamente.

Desse modo, as custas judiciais a serem dispendidas no processo, o tempo que a parte deve aguardar para o julgamento da causa, a possibilidade econômica das partes, a aptidão para reconhecer um direito e propor ação em sua defesa e a existência de litigantes eventuais e litigantes habituais tratam-se de enormes barreiras para o acesso da população à justiça, sobretudo em países tão marcados pela desigualdade, como é o caso da sociedade brasileira.

\section{SOLUÇÕES PRÁTICAS PARA OS PROBLEMAS DE ACESSO À JUSTIÇA NAS AÇÕES QUE PEDEM PRESTAÇÕES DA SAÚdE DO PODER PÚBLICO NO BRASIL}

É possível identificar a existência de traços comuns no modelo de proteção social predominante em vários países latino-americanos, que em geral se expressam nos sistemas de saúde. Dentre eles, podemos destacar a trajetória histórica predominantemente corporativa e fragmentada, vinculada à lógica de seguro (e não à lógica abrangente de seguridade), o peso importante dos gastos e da prestação privada de serviços, a centralidade das políticas de combate à pobreza a partir dos anos 1990 e as limitações das políticas sociais para superar as marcantes desigualdades, características dessas sociedades (MACHADO, 2011).

Com efeito, tal como adverte Bobbio, nem tudo o que é desejável e merecedor de ser perseguido é realizável. Para a realização dos direitos do homem são frequentemente necessárias condições objetivas que não dependem da boa vontade dos que proclamam, nem das boas disposições dos que possuem os meios para protegê-los. Sabe-se do enorme problema diante do qual estão hoje os países em desenvolvimento de encontrarem condições econômicas que, apesar dos programas ideais, não permitem desenvolver a proteção da maioria dos direitos sociais. Assim, a efetivação de uma maior proteção dos direitos do homem está ligada ao desenvolvimento global da civilização humana. É um problema que não pode ser isolado, sob pena, não só de deixar de resolver, mas de sequer compreende-lo em sua real dimensão. Quem o isola já perdeu (BOBBIO, 2004, p. 43-44). 
Contudo, impende destacar que não obstante o direito social fundamental à saúde seja norma constitucional de aplicação imediata (como apregoa o art. $5^{\circ}, \S 1^{\circ}$ da Constituição Federal), é inegável que ele possui conteúdo programático, na medida em que sua concretização se dá por meio de prestações positivas por parte do Estado, as quais são realizáveis por políticas públicas específicas. Portanto, a decisão política sobre a organização pública da saúde é de responsabilidade imediata do Poder Executivo e Legislativo, mormente o primeiro, nas três esferas da federação: União, Estados e Municípios (Lei 8.080/1990 e o Decreto $\mathrm{n}^{\circ}$ 7.508/2011). De qualquer forma, a conduta esperada por parte desses entes políticos é a efetiva alocação de recursos à área da saúde, sob pena de, em assim não o fazendo, ocasionar frustração às justas expectativas depositadas pela população. Por isso entende-se que o direito fundamental à saúde é dual (dupla dimensão), isto é, além de direito fundamental de todos é também um dever fundamental ao vincular o Poder Público à sua efetivação.

Note-se que as pessoas recorrem ao Poder Judiciário pedindo prestações referentes à saúde como remédios, cirurgias e tratamentos diante do não cumprimento do compromisso constitucional nessa área pelo Poder Executivo e Legislativo, fazendo com que o Poder Judiciário a concretize e implemente. Por meio do voto de Relatoria do Ministro Celso de Mello, o Supremo Tribunal Federal exarou novas luzes sobre a temática e expressamente enfatizou o dever do Poder Judiciário exprimir da Constituição Federal o direito à saúde e concretizá-lo. A propósito, o Supremo Tribunal Federal no RE n⿳0 271286 AgR/RS - AG.REG:

O direito público subjetivo à saúde representa prerrogativa jurídica indisponível assegurada à generalidade das pessoas pela própria Constituição da República (art. 196) (...). O direito à saúde - além de qualificar-se como direito fundamental que assiste a todas as pessoas representa consequiência constitucional indissociável do direito à vida. $\mathrm{O}$ Poder Público, qualquer que seja a esfera institucional de sua atuação no plano da organização federativa brasileira, não pode mostrar-se indiferente ao problema da saúde da população, sob pena de incidir, ainda que por censurável omissão, em grave comportamento inconstitucional. (BRASÍLIA. Supremo Tribunal Federal, 2000).

Assim, uma vez verificada a omissão do Poder Público no que diz respeito às prestações ao direito à saúde, deve o Poder Judiciário, quando instado, realizar a concretização do direito de acesso à justiça, atuar como construtor do direito e conceder a prestação de saúde reclamada. Por sua vez, considerando as peculiaridades das ações que pedem uma prestação 
estatal da saúde, requerendo remédios, cirurgias ou tratamentos específicos e a complexidade da organização do sistema de saúde público, fez com que os tribunais brasileiros adotassem uma série de procedimentos que visam facilitar o acesso à justiça nos pedidos de prestações referentes ao direito fundamental à saúde, o que se passa a explanar.

\subsection{1 OS CUSTOS DA DEMANDA NAS AÇÕES JUDICIAIS}

No direito brasileiro, a assistência jurídica integral e gratuita é um direito fundamental aos que comprovarem insuficiência de recursos ${ }^{2}$. Pedidos referentes ao direito à saúde no Poder Judiciário quase sempre tramitam sob o benefício da Justiça Gratuita, que dispensa o pagamento de custas, despesas processuais e honorários advocatícios. A Defensoria Pública, organizada de forma permanente e essencial à função jurisdicional do Estado, incumbe fundamentalmente a orientação jurídica, a promoção dos direitos humanos e a defesa, em todos os graus, judicial e extrajudicial, os direitos individuais e coletivos, de forma integral e gratuita (CF, art. 134, caput).

Do mesmo modo, ao permitir o cidadão litigar sob o benefício da assistência judiciária gratuita também é removido o obstáculo da desigualdade economica das partes e a inaptidão de reconhecer a existência de um direito e possibilidade de ajuizar ação em sua defesa, eis que o beneficiário será assistido por um defensor público ou advogado particular.

\subsection{2 O TEMPO DA DEMANDA}

A demora de um processo judicial pode representar um sério obstáculo ao acesso à justiça, sobretudo quando se demanda uma prestação estatal referente à saúde (periculum in mora).

Embora a Lei no 8.437, de 30 de junho de 1992, imponha limitações ao Poder Judiciário nas concessões de liminares conta a Fazenda Pública ${ }^{3}$, ao dispor que "não será cabível medida liminar que esgote, no todo ou em qualquer parte, o objeto da ação", nas ações que pedem alguma prestação referente ao direito à saúde este dispositivo cede lugar diante da existência

$1 \mathrm{CF}$, art. $5^{\circ}$ Todos são iguais perante a lei, sem distinção de qualquer natureza, garantindo-se aos brasileiros e aos estrangeiros residentes no País a inviolabilidade do direito à vida, à liberdade, à igualdade, à segurança e à propriedade, nos termos seguintes: (...)

LXXIV - o Estado prestará assistência jurídica integral e gratuita aos que comprovarem insuficiência de recursos; 2 Lei $n^{\circ} 8.437 / 92$, art. $1^{\circ}$ Não será cabível medida liminar contra atos do Poder Público, no procedimento cautelar ou em quaisquer outras ações de natureza cautelar ou preventiva, toda vez que providência semelhante não puder ser concedida em ações de mandado de segurança, em virtude de vedação legal.

(...)§ $3^{\circ}$ Não será cabível medida liminar que esgote, no todo ou em qualquer parte, o objeto da ação (...) 
de situações especiais, quando presente o risco de vida ou à saúde do particular. Neste sentido é a jurisprudência do Tribunal de Justiça do Estado do Rio Grande do Sul:

\begin{abstract}
A vedação à concessão de liminar contra a Fazenda Pública, nos casos em que se esgote no todo ou em parte o objeto da ação, contida no $\S 3^{\circ}$ do art. $1^{\circ}$ da Lei $8.437 / 92$, cede ante situações especiais, face ao princípio constitucional que garante a efetividade e a tempestividade da tutela jurisdicional. Agravo de Instrumento $N^{\circ}$ 70044422749, Sétima Câmara Cível, Tribunal de Justiça do RS, Relator: André Luiz Planella Villarinho, Julgado em 16/08/2011 (RIO GRANDE DO SUL. Tribunal de Justiça, 2011).
\end{abstract}

Assim, é justo afirmar que nestes casos o Poder Judiciário opera uma ponderação e hierarquia de valores entre a regra processual da proibição de concessão de liminares contra a Fazenda Pública que esgote o objeto da ação e o direito fundamental à saúde, com prevalência deste último.

\title{
3.3 3.3 POSSIBILIDADE DE FAZER O PEDIDO NO PODER JUDICIÁRIO, SEM NECESSIDADE DE PEDIR NA ESFERA ADMINISTRATIVA
}

A efetivação do direito fundamental à saúde se dá por meio de políticas públicas, conforme a redação do art. 196, caput, da Carta Magna:

\begin{abstract}
Saúde é direito de todos e dever do Estado, garantido mediante políticas sociais e econômicas que visem à redução do risco de doença e de outros agravos e ao acesso universal e igualitário às ações e serviços para sua promoção, proteção e recuperação.
\end{abstract}

Inobstante o art. 196 da Constituição Federal dizer que o direito fundamental à saúde é concretizado mediante políticas públicas, o Supremo Tribunal Federal na Ação de Descumprimento de Preceito Fundamental $n^{\circ} 45$ MC/DF entendeu que embora não seja atribuição institucional do Poder Judiciário formular políticas públicas, encargo em princípio dos Poderes Legislativo e Executivo, em situações excepcionais poderá esta incumbência ser atribuída:

\footnotetext{
Se e quando os órgãos estatais competentes, por descumprirem os encargos político- jurídicos que sobre eles incidem, vierem a comprometer, com tal comportamento, a eficácia e a integridade de direitos individuais e/ou coletivos impregnados de estatura constitucional, ainda que derivados de cláusulas revestidas de conteúdo programático (BRASÍLIA. Supremo Tribunal Federal, 2004).
}

Com a possibilidade de o Poder Judiciário intervir nas políticas públicas quando o Estado deixar de cumprir com a obrigação de fornecer as prestações estatais, seja por ação ou 
omissão, o Tribunal de Justiça do Estado do Rio Grande do Sul dispensou o particular de protocolar o pedido administrativo nas ações que pedem alguma prestação estatal referente à saúde. Neste sentido:

Falta de interesse de agir. Desnecessidade de prévio pedido na via administrativa para fins de caracterização do interesse de agir. Precedentes TJRS. Mérito. O direito à saúde é direito social (art. $6^{\circ}$ da $\mathrm{CF} / 1988$ ) e dever do Estado (art. $196 \mathrm{da}$ $\mathrm{CF} / 1988$ e 241 da CE/1989) e está intimamente ligado ao direito à vida e à dignidade da pessoa humana; tem estatura de direito fundamental, seja no sentido formal, seja no sentido material, nos termos do parágrafo primeiro do consagrado art. $5^{\circ}$ da Constituição da República. Apelação Cível No 70061476503, Terceira Câmara Cível, Tribunal de Justiça do RS, Relator: Eduardo Delgado, Julgado em 18/04/2016 (RIO GRANDE DO SUL, Tribunal de Justiça, 2016).

Sendo assim, a jurisprudência do referido tribunal supera a primeira barreira ao acesso à justiça nas ações que pedem uma prestação da saúde, isto é, a possibilidade de deduzir o pedido em juízo.

Nesse contexto se inserem as postulações no âmbito da saúde, visto que o cidadão, vendo frustrado seu direito à saúde, seja por não conseguir por parte do Estado os medicamentos necessários para fazer frente à moléstia que lhe acomete, seja por não obter tratamento e atendimento dignos, vem movimentando a máquina judiciária e exigindo deste Poder a concretização da promessa constitucional do direito fundamental à saúde. Sobre o protagonismo do Poder Judiciário nas demandas de saúde anote-se que:

\begin{abstract}
Toda esta deficiente atuação do Legislativo e do Executivo configura causa para a ascensão institucional do Poder Judiciário. O protagonismo do Judiciário em matéria de direito à saúde é também uma das facetas da crise do Estado Brasileiro. Ou seja, se o setor público não funciona adequadamente, o caminho é a judicialização (SCHULZE; NETO, 2015, p. 45).
\end{abstract}

Portanto, a partir da omissão do Estado em fornecer as prestações da saúde, o Poder Judiciário passou a ser o espaço onde a cidadania exigirá seus direitos, superando a vetusta tese de que não é atribuição dos juízes decidir sobre políticas públicas.

\title{
3.4 3.4 DA SOLIDARIEDADE ENQUANTO PRINCIPIO OU DA SOLIDARIEDADE DO SISTEMA
}

Nosso país é uma Federação formada pela União, Estados e Municípios ${ }^{4} \mathrm{Na}$ esteira do artigo 198 da Constituição Federal, são responsáveis pela gestão do SUS, a União, os Estados,

\footnotetext{
${ }^{4} \mathrm{CF}$, art. $1^{\mathrm{o}}$ A República Federativa do Brasil, formada pela união indissolúvel dos Estados e Municípios e do Distrito Federal, constitui-se em Estado Democrático de Direito e tem como fundamentos: (...)
} 
Distrito Federal e os Municípios. As atribuições específicas de cada ente federativo, por sua vez, encontram-se preconizadas de modo detalhado na Lei $12.401 / 2011$, a qual alterou a Lei 8.080/1990, e no Decreto 7.508/2011. Note-se que a distinção das competências entre os entes federativos deve ser entendida como modo de organização e prestação do serviço público de saúde, com o objetivo de atender, ao fim e ao cabo, o princípio da eficiência administrativa ${ }^{5}$.

Contudo, fundada na vulnerabilidade do particular, que não dispõe de recursos e conhecimento para descobrir a atribuição de cada ente federado no que diz respeito à complexidade do Sistema Único de Saúde, não obstante a previsão constitucional e legal a indicar uma distribuição das competências, prevalece o entendimento jurisprudencial no sentido de que a responsabilidade pela execução das políticas públicas de saúde é solidária, logo, não há litisconsórcio passivo necessário, litispendência, ou conexão entre demandas propostas pelo mesmo autor perante a justiça estadual ou federal, devendo ser examinado apenas o princípio da demanda, no sentido de que cabe ao demandante escolher contra quem quer litigar. Nesse sentido é a jurisprudência do Supremo Tribunal Federal:

RECURSO EXTRAORDINÁRIO. CONSTITUCIONAL E ADMINISTRATIVO. DIREITO À SAÚDE. TRATAMENTO MÉDICO. RESPONSABILIDADE SOLIDÁRIA DOS ENTES FEDERADOS. REPERCUSSÃO GERAL RECONHECIDA. REAFIRMAÇÃO DE JURISPRUDÊNCIA. O tratamento medico adequado aos necessitados se insere no rol dos deveres do Estado, porquanto responsabilidade solidária dos entes federados. O polo passivo pode ser composto por qualquer um deles, isoladamente, ou conjuntamente. REPERCUSSÃO GERAL NO RECURSO EXTRAORDINÁRIO 855.178. SERGIPE. RELATOR: MIN. LUIZ FUX. (BRASÍLIA. Supremo Tribunal Federal, 2015).

Note-se que a responsabilidade entendida pelos tribunais como solidária entre Municípios, Estados, Distrito Federal e União foi confirmada pela jurisprudência do Supremo Tribunal. Assim, pode-se concluir que o entendimento acima exarado torna efetivo o direito de acesso à justiça em favor do particular, visto que evitará a necessidade prévia de perscrutar a atribuição administrativa de cada ente federado no que diz respeito ao fornecimento de uma prestação da saúde.

\subsection{5 BLOQUEIO DE VALORES DO ERÁRIO SEM NECESSIDADEDE PRECATÓRIO}

\footnotetext{
${ }^{5} \mathrm{CF}$, art. 37. A administração pública direta e indireta de qualquer dos Poderes da União, dos Estados, do Distrito Federal e dos Municípios obedecerá aos princípios de legalidade, impessoalidade, moralidade, publicidade e eficiência e, também, ao seguinte: (Redação dada pela Emenda Constitucional no 19, de 1998) (...).
} 
A Constituição Federal dispõe, como regra geral, que os pagamentos devidos pela Fazenda Pública Federal, Estaduais, Distrital e Municipal, em virtude de sentença judiciária, far-se-ão exclusivamente na ordem cronológica de apresentação dos precatórios ${ }^{6}$, salvo quando o débito for de pequeno valor ${ }^{7}$.

Entretanto, considerando que em determinadas situações a espera resultaria em risco de vida ou agravamento da doença, excepcionalmente é autorizado o bloqueio de valores necessários para o cumprimento da decisão judicial, seja da liminar ou da sentença, sem a necessidade de aguardar o precatório judicial ou a requisição de pequeno valor, visto que se fosse necessário esperar estes trâmites, o prejuízo à saúde do autor seria evidente, resultando prejudicado o acesso à justiça nas ações que pedem uma prestação estatal da saúde. Neste sentido:

\begin{abstract}
APELAÇÃO CÍVEL. REEXAME NECESSÁRIO. DIREITO PÚBLICO NÃO ESPECIFICADO. SAÚDE. PROCEDIMENTO CIRÚRGICO. PRELIMINAR DE ILEGITIMIDADE PASSIVA. REJEIÇÃO. RESPONSABILIDADE SOLIDÁRIA DOS ENTES FEDERATIVOS. PRECEDENTES JURISPRUDENCIAIS. CONDENAÇÃO DO MUNICÍPIO NA VERBA HONORÁRIA EM FAVOR DA DEFENSORIA PÚBLICA. AUSÊNCIA DE CONFUSÃO ENTRE CREDOR E DEVEDOR. MANUTENÇÃO. BLOQUEIO DE VALORES DA FAZENDA PÚBLICA PARA CUMPRIMENTO DE ORDEM JUDICIAL. CABIMENTO. Apelação n ${ }^{\circ} 70061838967$ Tribunal de Justiça do RS, Relator: Eduardo Delgado, Julgado em 18/04/2016 (RIO GRANDE DO SUL, Tribunal de Justiça, 2016).
\end{abstract}

O mesmo entendimento aplica-se para a possibilidade de o Poder Judiciário cominar multas, caso de a Administração não cumprir a ordem judicial, porquanto se assim não fosse, seria incentivada a desobediência ao Poder Judiciário, inviabilizando o acesso à justiça nas ações referente à saúde.

\title{
3.6 3.6 DO NÃO ESTIGMA DO DIREITO À SAÚDE
}

Destaca-se que em razão dos princípios da universalidade de acesso aos serviços de saúde, da integralidade das ações e serviços preventivos e curativos de saúde e da igualdade da

\footnotetext{
${ }^{6} \mathrm{CF}$, art. 100. Os pagamentos devidos pelas Fazendas Públicas Federal, Estaduais, Distrital e Municipais, em virtude de sentença judiciária, far-se-ão exclusivamente na ordem cronológica de apresentação dos precatórios e à conta dos créditos respectivos, proibida a designação de casos ou de pessoas nas dotações orçamentárias e nos créditos adicionais abertos para este fim. (Redação dada pela Emenda Constitucional $\mathrm{n}^{\circ}$ 62, de 2009). (Vide Emenda Constitucional $\mathrm{n}^{\circ}$ 62, de 2009) (...).

${ }^{7} \mathrm{CF}$, art. $100, \S 3^{\circ} \mathrm{O}$ disposto no caput deste artigo relativamente à expedição de precatórios não se aplica aos pagamentos de obrigações definidas em leis como de pequeno valor que as Fazendas referidas devam fazer em virtude de sentença judicial transitada em julgado. (Redação dada pela Emenda Constitucional $\mathrm{n}^{\circ}$ 62, de 2009) (...).
} 
assistência à saúde, sem preconceito de qualquer espécie, o direito à saúde vem sendo entendido e aplicado pelos poderes constituídos, em especial pelo Poder Judiciário, sem a estigmatização do pobre; vale dizer, o serviço público de saúde é devido a todos os indivíduos que estejam em território nacional, sejam ricos ou pobres.

Portanto, desinteressa as condições de renda do beneficiário para obtenção da política pública de saúde, eis que o Sistema Único de Saúde tem como característica a universalidade, bastando a condição de cidadão para ser elegível aos seus serviços.

\section{AMPLIANDo O ACESSO À JUSTIÇA E DIMINUINDo A DistânCIA DOS PODERES}

Conforme expomos supra, o Poder Judiciário, só será acionado em razão do Estado deixar de concretizar o direito fundamental à saúde. Neste sentido, considerando a importância do direito fundamental à saúde o Poder Judiciário adotou uma série de procedimentos visando facilitar o acesso à justiça com o fim de efetivar o direito fundamental à saúde em favor do cidadão.

Por outro lado, o número de demandas que pedem alguma prestação referente ao direito à saúde ajuizadas perante o Poder Judiciário no Brasil aumentou significativamente. Apenas para exemplificar, citemos o relato de uma juíza da Comarca de Araguaína - TO (JUDICIALIZAÇÃO DA SAÚDE NO BRASIL, 2015, p. 49):

\footnotetext{
Cheguei aqui e já deparei com algumas ações sobre saúde. Esse era um tema muito novo, eu não tinha conhecimento nenhum sobre direito sanitário. $\mathrm{O}$ único conhecimento que eu tinha era o artigo 196 da Constituição que, em regra geral, é conhecido por toda a classe jurídica. Começaram a pedir medicamentos com prescrição médica, eu comecei a deferir achando que estava correto. Só que começou a crescer de uma forma astronômica.
}

Outro exemplo do crescente número de feitos cujo objeto é o pedido de medicamentos é o do Estado do Rio Grande de Sul, onde atualmente tramitam oitenta mil processos relacionados ao tema (GLOBO, 2015).

Desse modo, diante do crescente número de demandas referente às prestações da saúde, o Poder Judiciário brasileiro atualmente se concentra em construir arranjos institucionais com o fim de que o direito fundamental à saúde seja atendido no âmbito da própria administração pública. Estes arranjos institucionais iniciam com a construção de um projeto fundamentado na ideia de que o direito à saúde deve ser concretizado pela 
Administração, eis que prioritariamente é a quem cabe a responsabilidade pela execução das políticas públicas.

Ações concretas destes arranjos institucionais iniciam com a ouvida dos atores interessados no tema, como juízes, defensoria pública, procuradorias do estado e municípios, Ministério Público, gestores do Sistema Único de Saúde e membros do conselho municipal de saúde com o fim de identificar os problemas para efetivar o direito fundamental à saúde. Os arranjos institucionais incentivam a maior divulgação das informações básicas à população sobre o sistema público de saúde, visto que muitas demandas são ajuizadas desnecessariamente em razão da falta de conhecimento da população e mesmo dos servidores sobre o funcionamento do Sistema Único de Saúde.

Assim, os arranjos institucionais objetivam promover ações preventivas em âmbito administrativo com o fim de propiciar que a administração atenda as prestações referentes à saúde com eficiência, sem a necessidade de intervenção judicial, reservando ao Poder Judiciário brasileiro agir apenas no caso da falta do efetivo fornecimento da prestação da saúde.

\section{CONCLUSÃO}

O Estado, na sua concepção liberal, não se preocupava com a questão do acesso à justiça, eis que considerava o acesso à justiça um direito natural, sendo assim não precisava de uma intervenção do Estado para sua proteção. Desse modo, trata-se de um período marcado pela passividade do Estado em relação a possibilidade de uma pessoa reconhecer e defender seus direitos no caso concreto.

Contudo, com o advento do Estado Democrático de Direito, o acesso à justiça, na prática, passou a ser preocupação e várias medidas legislativas foram tomadas com o objetivo de efetivamente propiciar a concretização dos direitos. Com este escopo foi concedida gratuidade da justiça aos que não podiam pagar custas, despesas e honorários de advogado, o ônus da prova foi redistribuído em razão da condição pessoal da parte que recorre à justiça, passou-se, enfim, a entender que não basta a previsão legal dos direitos, é preciso criar as condições para que seja possível o acesso à justiça.

Por outro lado, diante da complexidade cada maior da nossa sociedade, não se pode mais dizer que o acesso à justiça pode ser concretizado com fórmulas prontas que sirvam a todos os casos. Embora muitos obstáculos para o acesso à justiça foram removidos por modificações nas leis, há determinados direitos fundamentais, que pela sua complexidade, é 
preciso ir além dos preceitos clássicos preconizados pelo acesso à justiça, pois estes, por si só, já não representam garantia de que a parte concretizará seu direito, na prática.

Trata-se do caso do acesso à justiça nas ações que se pedem alguma prestação referente à saúde perante o Poder Judiciário. Percebeu-se que nestes casos as fórmulas clássicas de propiciar o acesso à justiça não funcionariam diante da complexidade do Sistema Único de Saúde e adotou-se uma série de procedimentos que visam beneficiar o cidadão, assegurando-lhe maior possibilidade de obter a prestação jurisdicional. São os casos da solidariedade dos entes públicos para fornecer as prestações referentes à saúde, possibilidade de bloqueio de valores do Erário para concretizar o pedido da parte e a não estigmatização do cidadão necessitado no Poder Judiciário.

Entretanto, embora sejam positivas, as medidas adotadas para concretizar o acesso à justiça às ações da saúde trouxeram outro efeito: o crescente número de demandas no Poder Judiciário fazendo-se substituir por vezes o papel do gestor público da saúde. Percebeu- se assim que, sozinho, o juiz não consegue e nem pode agir como administrador, eis que não é esta sua função constitucional como membro do Poder Judiciário. Anote-se, ainda, que o congestionamento do Poder Judiciário prejudica o próprio jurisdicionado diante do maior tempo para a entrega da prestação jurisdicional, sobretudo quando se trata com a questão da saúde.

Assim, sem abdicar dos avanços conquistados pelo acesso à justiça, agora busca-se um maior diálogo e colaboração entre administração e o Poder Judiciário com o fim de efetivar o direito fundamental à saúde. $\mathrm{O}$ juiz deixa a atividade passiva da jurisdição e passa a integrar ativamente como um agente transformador da realidade do Sistema Único, o que resulta numa maior eficiência da prestação do serviço público de saúde. Neste sentido, jurisdição e administração não são mais antagônicas e sim parceiras na solução da gestão pública, com o objetivo de concretizar o acesso à justiça nas ações que pedem prestações da saúde perante o Estado.

Com esta dinâmica, o direito brasileiro vai além das medidas clássicas de acesso à justiça e adota procedimentos próprios, reduzindo a distância entre o Poder Executivo e Judiciário para efetivar os direitos dos cidadãos quando pedem uma prestação da saúde, tratando-se de uma experiência que poderia, com as devidas adaptações, servir de aprimoramento das políticas públicas e instituições de saúde da América Latina.

\section{BIBLIOGRAFIA}


AARON, Henry; SCHWARTZ, William. The painful prescription: rationing hospital care. Washington, DC: The bookings institution, 1984.

ABRAHÃO, Ana et al. Políticas de Saúde: organização e operacionalização do Sistema Único de Saúde. Rio de Janeiro: Fiocruz. 2007. Disponível em http://www.epsjv.fiocruz.br/index.php?Area=Material $\& M N U=\& T i p o=8 \& N u m=25$ Acesso em 5 de junho de 2016.

AMARAL, Gustavo. Direito, escassez e escolha. Critérios jurídicos para lidar com a escassez de recursos e as decisões trágicas. 2, ed. Rio de Janeiro: Lumen Juris, 2010.

BARROSO, Luis. A dignidade da pessoa humana no direito constitucional contemporâneo. Belo Horizonte: Fórum, 2013.

BLIACHERIENE, Ana.; Santos, José. Direito à Vida e à Saúde. São Paulo: Atlas. 2010. BOBBIO, Norberto. A era dos direitos. 9a ed. Rio de Janeiro: Elsevier, 2004.

BRASIL. Decreto $n^{\circ} 7.508$, de 28 de junho de 2011. Disponível em http://www.planalto.gov.br/ccivil_03/_ato2011-2014/2011/decreto/D7508.htm Acesso em: 5 de jun. de 2016.

BRASIL. Lei n 8.080, de 19 de setembro de 1990. Disponível em

http://www.planalto.gov.br/ccivil 03/leis/L8080.htm Acesso em: 5 de jun de 2016.

BRASIL. Lei no 8.437 , de 30 de junho de 1992. Disponível em

http://www.planalto.gov.br/ccivil 03/leis/L8437.htm Acesso em: 5 de jun de 2016.

BRASIL. Lei no 12.401, de 28 de abril de 2011. Disponível em

http://www.planalto.gov.br/ccivil 03/ Ato2011-2014/2011/Lei/L12401.htm Acesso em: 5 de jun de 2016.

BRASÍLIA. Supremo Tribunal Federal, 2000. RE 271286 AgR / RS - RIO GRANDE DO SUL AG.REG.NO RECURSO EXTRAORDINÁRIO. Disponível em http://www.stf.jus.br/portal/jurisprudencia/listarJurisprudencia.asp?s1=\%28RE\%24\%2ESCL $\mathrm{A} \% 2 \mathrm{E}+\mathrm{E}+271286 \% 2 \mathrm{ENUME} \% 2 \mathrm{E} \% 29+\mathrm{OU}+\% 28 \mathrm{RE} \% 2 \mathrm{EACMS} \% 2 \mathrm{E}+\mathrm{ADJ} 2+271286 \% 2 \mathrm{EA}$ CMS\%2E\%29\&base=baseAcordaos\&url=http://tinyurl.com/ah6x5gl Acesso em: 25 de maio de 2016.

BRASÍLIA. Supremo Tribunal Federal, 2004. ADPF nº 45. Disponível em http://www.stf.jus.br/portal/jurisprudencia/listarJurisprudencia.asp?s1=\%28ADPF\%24\%2ESC $\underline{\mathrm{LA}} \% 2 \mathrm{E}+\mathrm{E}+45 \% 2 \mathrm{ENUME} \% 2 \mathrm{E} \% 29+\mathrm{NAO}+\mathrm{S} \% 2 \mathrm{EPRES} \% 2 \mathrm{E} \&$ base=baseMonocraticas \&url= http://tinyurl.com/a9kzfpa Acesso em: 30 de maio de 2016.

BRASÍLIA. Supremo Tribunal Federal, 2015. RE nº 855178 Disponível em http://www.stf.jus.br/portal/processo/verProcessoAndamento.asp?incidente $=4678356$ Acesso em: 30 de maio de 2016. 
CAPPELLETTI, Mauro; GARTH, Bryant. Acesso à justiça. Porto Alegre: Livraria do Advogado, 2002.

CASA RUI BARBOSA. Disponível em http://www.casaruibarbosa.gov.br/dados/DOC/artigos/rui barbosa/FCRB RuiBarbosa Oraca o_aos_mocos.pdf Acesso em: 27 de maio de 2016.

COMPARATO, F. A afirmação histórica dos direitos humanos. $7^{\circ}$ ed. São Paulo: Saraiva, 2010.

CONSELHO NACIONAL DE JUSTIÇA. JUDICIALIZAÇÃO DA SAÚDE NO BRASIL. Disponível em

http://www.cnj.jus.br/files/conteudo/destaques/arquivo/2015/06/6781486daef02bc6ec8c1e491 a565006.pdf Acesso em: 5 de jun de 2016.

CONSULTOR JURÍDICO. Disponível em http://www.conjur.com.br/2015-ago-10/volumeacoes-envolvendo-estado-prejudicam-acesso-justica Acesso em: 24 de abr de 2016.

DANIELS, Norman. Just health care. New York: Cambridge University Press, 1995.

DWORKIN, Ronald. Levando os direitos a sério. São Paulo: Martins Fontes. 2010.

FARIA, José. Direitos humanos, direitos sociais e justiça. São Paulo: Malheiros, 2005.

GLOBO. RS é o estado brasileiro com mais processos por remédios na Justiça. Disponível em http://g1.globo.com/rs/rio-grande-do-sul/noticia/2015/03/rs-e-o-estado-brasileiro-com-maisprocessos-por-remedios-na-justica.html Acesso em: 5 de jun de 2016.

HABERMAS, Jürgen. Direito e democracia entre facticidade e validade. v. I. 2. ed. Rio de Janeiro: Tempo Brasileiro, 2012.

LOPES, José. Direitos sociais. Teoria e Prática. São Paulo: Método, 2006.

MACHADO, Cristiane Vieira. Ciência \& Saúde Coletiva. v. 16 n $^{\circ}$ 6. Rio de Janeiro. Junho 2011. Disponível em http://www.scielo.br/scielo.php?script=sci_arttext\&pid=S141381232011000600004 Acesso em: 29 de maio de 2016.

RIO GRANDE DO SUL. Tribunal de Justiça, 2011. Agravo de Instrumento nº 70044422749 , Sétima Câmara Cível. Relator: André Luiz. Julgado em 16/08/2011.

RIO GRANDE DO SUL, Tribunal de Justiça, 2016. Apelação Cível nº 70061476503, Terceira Câmara Cível, Relator: Eduardo Delgado, Julgado em 18/04/2016.

ROSSEAU, Jean. O contrato social. São Paulo: Martins Fontes, 1989.

SARLET, Ingo. A eficácia dos direitos fundamentais. $10^{\mathrm{a}}$ ed. Porto Alegre: Livraria do Advogado, 2010. 
SARLET, Ingo. Dignidade da pessoa humana e direitos fundamentais. $9^{\mathrm{a}}$ ed. Porto Alegre: Livraria do Advogado, 2012.

SARLET, Ingo. Os direitos sociais fundamentais na Constituição de 1988. Revista Diálogo Jurídico. Salvador: v. 1, nº 1, p. 1-45, 2001.

SCHULZE, Clenio Jair; GEBRAN NETO, João Pedro. Direito à saúde- Análise à luz da judicialização. Porto Alegre: Verbo Jurídico, 2015.

SUNSTEIN, Cass; HOLMES, Stephen. The Cost of Rights. Why Liberty Depends on Taxes. New York: W.W. Norton \& Company. 2000. 